\title{
HEAVY METALS IN THE ECOSYSTEM COMPONENTS AT "DEGELEN" TESTING GROUND OF THE FORMER SEMIPALATINSK TEST SITE
}

\author{
A.B. Yankauskas ${ }^{1 *}$, S.N. Lukashenko ${ }^{1}$, A.A. Amirov ${ }^{1}$, P.V. Govenko ${ }^{1}$ \\ ${ }^{1}$ Institute of Radiation Safety and Ecology NNC RK, Kurchatov, Kazakhstan \\ *Yankayskas@nnc.kz,8(72251)2-27-20
}

\begin{abstract}
The ecological situation in the former Semipalatinsk test site is characterized by a combination of both radiative and "nonradiative" factors. There were investigated near-portal areas of the tunnels with water seepage at "Degelen" site. All the tunnel waters are characterized by higher concentrations of uranium, beryllium, and molybdenum. The watercourse of the tunnel \# 504 is unique for its elemental composition, in particular, the content of rare earth elements, whose concentration in the water is in the range $n^{*} 10^{-5}-\mathrm{n} * 10^{-7} \%$. Of all the rare earth elements in the samples were found 13 , the concentrations of aluminum, manganese, zinc are comparable to the concentrations of macro-components. Concentration of ${ }^{238} \mathrm{U}$ in the studied waters lie in the range of $\mathrm{n}^{*} 10^{-4}-\mathrm{n}^{*} 10^{-6}$ $\%$, which suggests the influence of uranium, not only as a toxic element, but its significance as the radiation factor. The analysis of complex data obtained showed that the elevated concentrations of heavy metals in the soils of the areas under study, as a rule, are a consequence of the carry-over of these metals by water flows and their subsequent deposition in the sediments.
\end{abstract}

Keywords: tunnel, lanthanides, element, STS, Degelen.

\section{Introduction}

The Semipalatinsk test site is one of the three largest testing sites in the world. The nuclear tests were conducted not throughout the range, but on the testing grounds. A total of 456 nuclear tests (616 nuclear explosions) were carried out. The total area of the STS is $18500 \mathrm{~km}^{2}$. "Degelen" site was used for nuclear testing of medium and small capacity. The site is located on the same mountain range, which is a dome-shaped elevation with the size of 17-18 km in diameter; total area is about $300 \mathrm{~km}^{2}$. The underground nuclear tests were conducted in tunnels. A tunnel is a horizontal excavation in length from a few hundred meters to $2 \mathrm{~km}$, with a hole diameter of about 3 meters. Total for the period 1961-1989 209 nuclear tests was conducted in 181 tunnels. From 1996 to 1998 at "Degelen" site operations on the closure of the tunnels were carried out [1].

For many years, the Semipalatinsk test site has been thought to be a source of radiation hazard, excluding the effect of other factors on the environment. However, there is evidence of high concentrations of heavy metals in soil and water [2].

The areas adjacent to the mountain range "Degelen" were investigated during 2 years, more than 40 chemical elements were studied. Abnormally high contents of a number of elements were revealed. Areal distribution of the elements by their concentrations is differentiated, expressed by local spots of irregular shape in all areas [2].

In addition, in the STS there is evidence of finding the deposits of minerals such as tungsten, beryllium, and molybdenum. There are zirconium, antimony, and tin. The western slope of the Degelen Mountains has a group of greisen bodies with a tungsten mineralization forming the ore field. The greatest number of greisen bodies enclosing rare-metal mineralization is concentrated on Southern and Northern parts. The ores contain wolframite, hematite, pyrite, sphalerite, galena, scheelite, molybdenite, beryl and other minerals. Thus, the study of heavy metals in the components of the ecosystem, having a negative impact on the natural environment, is necessary [2].

Many of the tunnels at "Degelen" site are characterized by having water seepage. The watercourses are observed in more than 50 tunnels. The watercourses are seasonal and occur in autumn and spring seasons. Continuous water seepage is observed in 8 tunnels: \# 104, 165, 176, 177, 504, 506, 511, 609, which were selected as objects of study (Figure 1) [1].

The goal of this paper is to investigate the contamination levels of the ecosystem components with heavy metal and mechanisms of its formation.

To achieve the goal there were investigated the vegetation and soil, made geobotanical description of the near-portal areas of tunnels with water seepage at "Degelen" site, determination of communities and dominant plant species growing in the area adjacent to the near-portal areas and stretching all the way along the stream. The chemical composition of tunnel water, the content of heavy metals in soil and vegetation, as well as the contamination mechanism of the ecosystem components with heavy metal were investigated. To assess the mechanisms for contamination levels of soil and vegetation with heavy metal there were analyzed samples of soils, plants, taken from the profiles of watercourses perpendlcularly crossing the bed from where water flows out to the surface and to the end of the channel. 


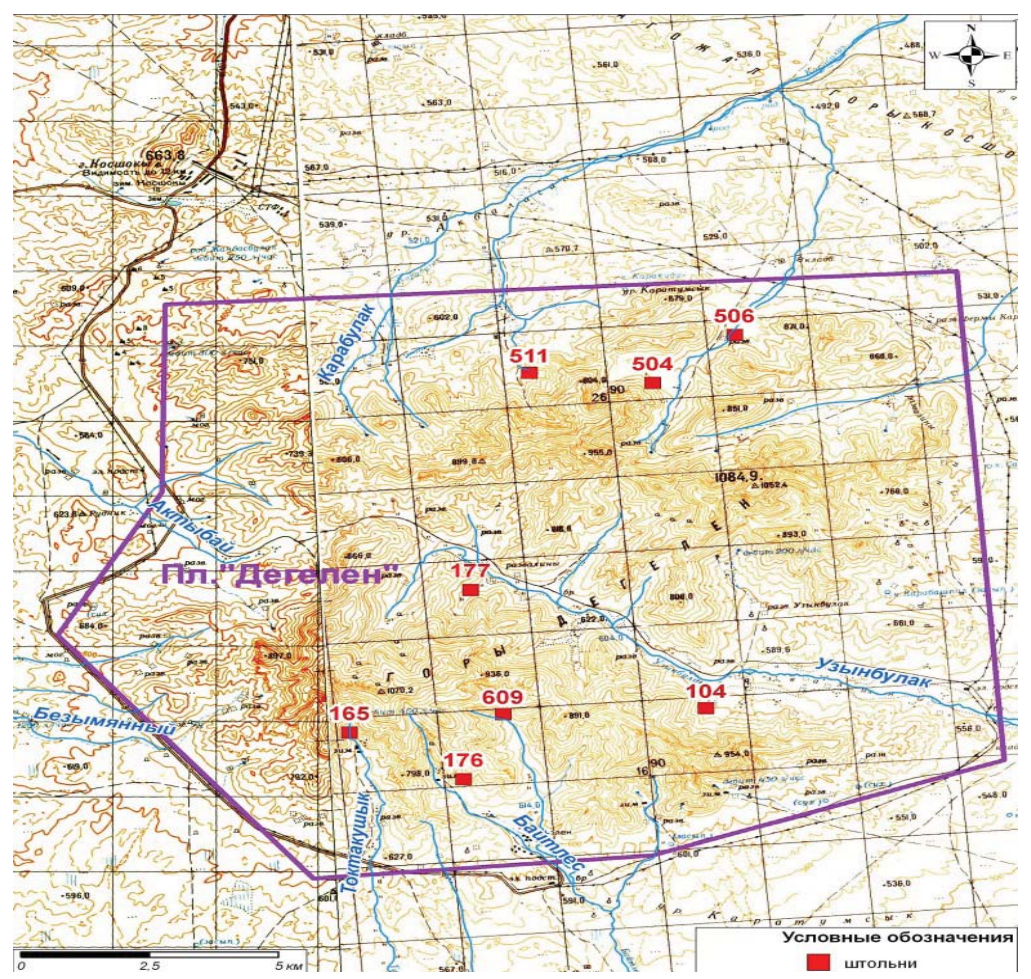

Figure 1. Location of the tunnels with water seepage at "Degelen" Mountains Massif

\section{Experimental Part}

The tunnel water, soil and plants were selected as subject of research.

Sampling of water. To assess the content and changes in the concentration of heavy metals in the water the water samples were collected where the watercourse flows out to the surface. Each month, a different amount of water samples were taken due to changes in water flow rate of the watercourse at each tunnel.

In order to assess changes in the concentration of heavy and toxic elements in water down-stream in the period 2010 - 2011 water samples were taken at the point where the watercourse flows out to the surface and every 50 meters watercourse downstream to a distance of $300 \mathrm{~m}$.

The water was sampled in accordance with GOST 17.1.5.05-85 "General requirements for sampling of surface and marine waters, ice and atmosphere". The main activities at water sampling were: water filtration to remove mechanical impurities through a paper filter "white ribbon" (lit. "belaya lenta"), conservation of samples by adding concentrated "highly pure" nitric acid $\left(\mathrm{HNO}_{3}\right)$ at a rate of $3 \mathrm{ml}$ of $\mathrm{HNO} 3$ to 1 liter of water sample. Water samples were collected in clean polypropylene 1 litre bottles with screw-cap. Conservation and filtration of the samples were conducted at sampling site. The conserved samples were stored prior to analysis in a cool dark place for 2-7 days [1].

Soil sampling. To determine the level of soil contamination at the estuarine areas of the tunnels at Degelen mountain massif the soil at tunnel № 177, 504 was sampled. Sampling was carried out as follows: on the profiles (each tunnel had 7 profiles, each profile had 5 points) perpendicularly to the direction of a stream bed, the distance between the profiles is $50 \mathrm{~m}$, the sampling step is $10 \mathrm{~m}$. The central sampling point was laid directly in the stream bed. Samples were collected by puncture with a metal soil sampler. The depth of sampling is $0-5 \mathrm{~cm}$ and sapling area is $100 \mathrm{~cm}^{2}$.

To determine the boundaries of soil contamination near the tunnel \#504 the soil samples were collected along the streambed with a broader area of the point locations than in 2010, since according to the last year data the area of contamination at the near-portal area was much higher than expected. Thus, sampling was carried out on the profiles ( 3 profiles, 5 points at each profile) perpendicularly to the direction of a streambed, the distance between the profiles is $200 \mathrm{~m}$, the sampling step is $100 \mathrm{~m}$. Samples were collected in accordance with GOST 17.4.3.01-83 "The Nature Conservancy. The soil. General requirements for sampling”. There were taken 20 soil samples. Soil sampling was carried out by puncture with a depth of $0-5 \mathrm{~cm}[3,1]$ 
Sampling of plants. To study the migration of heavy metals in the system "soil - plant" several near-port sites were investigated. The vegetation cover was described, the communities and dominant species were identified $[1,2]$. In the territory under study the following plants were sampled: bush grass (Calamagróstis epigéjos), southern reed (Phragmites austrális), naked-leaved briar (Rosa glabrifolia), weeping birch (Bétula péndula), gray willow (Salix cenerea). The plants were collected at different sites, conventionally separated by contents of heavy metals and radionuclides in the soil. The plants were taken according to profiles previously laid for the soil sampling (7 profiles, 5 points at each profile). Each profile crossed the stream bed perpendicularly to flow. The profiles for plant sampling were placed in the same points as for the soil samples. The number of points in the profiles for the plant samples depended on species diversity. The number of sampling points in each profile ranged from 2 to 5 , depending on the species grown. Sine qua non was the discovery of at least one recurring species for all the profiles for comparative analysis for heavy and toxic elements as distance from the center of the bed and the tunnel portal. All the requirements were met by such plant species as bush grass (Calamagróstis epigéjos). The plant samples were collected from $1 \mathrm{~m}^{2}$.

Preparation of water samples for analysis. Preparation of the water samples directly before the analysis was as follows: $20 \mathrm{ml}$ aliquot of solution was taken, diluted in a ratio of 1:5 and analyzed for the content of elements interested.

Preparation of soil samples for analysis. The soil samples preparation consisted of drying the soil, grinding and acid leaching. The soil samples were dried in an oven at $70^{\circ} \mathrm{C}$ for 5 hours. Then, for grinding purpose a $100 \mathrm{~g}$ weighed sample was taken from the dried sample by the method of quartering. The grinding was carried out manually by the abrasion of the sample in a porcelain dish to a particle size $\leq 250$ mesh.

Leaching was conducted in accordance with "Methods of sample preparation in analytical autoclave NPVF "Ancon-AT-2. The soil. Biological objects of analysis" (MI 2339-95, VNIIMS, Moscow).

A $200 \mathrm{mg}$ weighed sample was placed in a Teflon liner and was added in small portions of $10 \mathrm{~cm}^{3} 7 \mathrm{M}$ nitric acid. Then the Teflon liner was inserted in a Teflon "bomb" and autoclave decomposition was made for $2.5 \mathrm{~h}$ at $150 \mathrm{C}$. After autoclaving, cooled sample was transferred to a centrifuge tube and centrifuged for $10 \mathrm{~min}$ at a frequency of rotation of $4000 \mathrm{rpm}$, then the centrifugate was transferred in a $15 \mathrm{~cm}^{3}$ measuring tube, and the precipitate was washed with $5 \mathrm{~cm}^{3}$ $7 \mathrm{M}$ nitric acid and again centrifuged. The centrifugate and wash solution was combined and brought to a volume of 15 $\mathrm{cm}^{3}$ with 7M nitric acid. Thus obtained stock solution and diluted 1:10 was analyzed for chemical elements [3,4].

Preparation of plant samples for analysis. Preparation of plant samples consisted of weighing (green weight), washing of each sample with distilled water, drying, grinding, homogenization, determination of dry weight, sifting through a sieve with a diameter of $0.200 \mathrm{~mm}$. Next up to $5 \mathrm{~g}$ weighed samples were taken, then weighed on an analytical balance at 2 replications with mass of $0.5-1$, and decomposed by the acid autoclave decomposition.

Acid decomposition of plant samples for elemental analysis was as follows:

A weighed sample of $0.5 \mathrm{~g}$ of dried (grinded) analytical sample was placed into a reaction glass, wetted with bidistilled water and then nitric acid in an amount of $5 \mathrm{ml}$ was added. The weighed sample was placed in an autoclave and heated in a laboratory oven during 30 minutes. After that, the weighed sample in a collection container (glass) was placed in a drying oven heated to a temperature of $160 \pm 2^{\circ} \mathrm{C}$ and was heated for 2.5 hours. For the control experiment (blank) another reaction glass was placed a $6 \mathrm{~cm}^{3}$ of concentrated nitric acid without addition of sample and $1 \mathrm{ml}$ bidistilled water. At the end of the decomposition process the containers were cooled to room temperature. After that the weighed sample was added $1.5 \mathrm{~cm}^{3}$ of hydrogen peroxide. The blank sample underwent the same procedure. Then the weighed samples were again dried in the drying oven for 1.5 hours. Further the cooled to room temperature weighed sample were transferred to a measuring flask and was adjusted to a volume of $15 \mathrm{~cm}^{3}$ with $1 \%$ solution of nitric acid and packed in polypropylene tubes with screw caps (vials).

If there was a precipitate the solution was centrifuged, the supernatant fluid was transferred into a measuring tube, and then the volume was adjusted to $15 \mathrm{~cm}^{3}$ with $1 \%$ solution of nitric acid, was stirred and transferred to vials.

The metals were determined in the sample, diluted (1:5) by bidistilled water according to ISO 17294-2 method "Water quality - Application of mass spectrometry with inductively coupled plasma. Part 2: Determination of 62 elements". The samples were diluted using dispenser with disposable tips and polypropylene tubes with screw caps.

The analytical work. The heavy metals and toxic elements were measured by ICP-MS and ICP-ES, using a quadrupole mass spectrometer Elan 9000 manufactured by «Perkin Elmer SCIEX», complete with a computer and specialized software. The device is equipped with a standard spray chamber Scott with the cross-stream spray and single-collector two-segment detector of ions (without the dynamic reaction cell) or by using an optical atomic emission 
spectrometer iCAP 6300 DUO made by Thermo Scientific complete with a computer and specialized software. The device is equipped with a cyclone spray chamber with a cross-stream spray and CID semiconductor detector [3].

To construct the calibration diagrams there were used multi-elemental reference standards, registered in the RK State System for Ensuring Uniform Measurement № KZ.03.02.00902-2010, KZ. 03.02.00901-2010. The measurement quality control was carried out by measuring the calibration solution after every 10 samples. If unsatisfactory calibration results occurred (deviation of calibration curve by 8-10\%) the device was subjected to re-calibration.

The analysis was conducted to determine the elements according to the method ISO 17294-2:2003 (E) (state registration number 022/10505 from 27.12.05).

Thus, there were analyzed samples of water, plants and soil leached solutions, determined the content of the following elements $\mathrm{Na}, \mathrm{Mg}, \mathrm{K}, \mathrm{Ca}, \mathrm{Al}, \mathrm{Li}, \mathrm{Be}, \mathrm{Sc}, \mathrm{Cr}, \mathrm{Mn}, \mathrm{Fe}, \mathrm{Co}, \mathrm{Ni}, \mathrm{Cu}, \mathrm{Zn}, \mathrm{Ga}, \mathrm{As}, \mathrm{Se}, \mathrm{Rb}, \mathrm{Sr}, \mathrm{Y}, \mathrm{Mo}, \mathrm{Ag}, \mathrm{Cd}, \mathrm{Cs}$, $\mathrm{Ba}, \mathrm{La}, \mathrm{Ce}, \mathrm{Pr}, \mathrm{Nd}, \mathrm{Sm}, \mathrm{Eu}, \mathrm{Gd}$, Tb, Dy, Ho, Er, Tm, Yb, Lu, Re, Tl, Bi, U. The analysis was performed according to the method ISO 17294-2:2003 (E) (state registration number 022/10505 dated 27.12.05). Macro components (Na, K, Mg, $\mathrm{Ca}$ ) were analyzed in solutions obtained by diluting the stock solutions 10 and 100 times.

\section{Results and discussion}

Tunnel waters. Table 1 lists the average concentrations of microelements in the tunnel waters at "Degelen" site for 2010-2011. Additionally it shows the values of maximal allowable concentrations for water in Kazakhstan. Sampling in 2010 and 2011 was conducted in the same locations (at the exit point of the watercourse to the surface), about the same time of year (Table 1) [3,4].

It should be noted that the contents in water of such elements such As, Se, $\mathrm{Ag}, \mathrm{Tl}$ are at levels below the detection limit, which were for As - 0,006 mg/L, for Se - 0,06 mg/l, for Ag - 0,0005 mg/l, and for Tl - 0,0003 mg/l. Thus, for the past 2 years, the chemical composition of the tunnel waters has unchanged, despite fluctuations in the concentrations of some elements. No evident about the elements previously detected in the tunnel waters have been reported - for example, for rare-earth elements in the tunnels 104, 165, 176, 177, 506, 511, 609 the concentrations remain at levels below the detection limit. The concentrations of such elements as uranium, beryllium, and molybdenum remain high.

Concentrations of beryllium in some cases (for tunnels 104, 176, 504) increase by 20-30\% compared to 2010 and decrease by $10-20 \%$ (in the tunnels 511, 609). Content of in lithium and molybdenum in the tunnel waters increased slightly compared with 2010, from a few to tens of percent in some cases. However, the concentrations remain at the same level as in 2010, and such changes are natural and are associated with changes in the chemical composition of groundwater under the influence of different factors over time.

The concentration of uranium markedly decreased in the tunnel waters compared with 2010, an average of almost 3.5 times. Probably this change is due to seasonal groundwater recharge from atmospheric precipitations, which make the reaction of groundwater medium $[9,3,6,7,4]$ more neutral and, therefore, the leaching of uranium is less - it is likely that groundwater recharge by atmospheric precipitation in 2011 was higher than in 2010 .

The analysis of the water in the tunnel \# 504 confirms the presence of lanthanum elements, anomalous content of manganese, aluminum, and zinc. Based on data from 2010 and 2011, we can assume that the causes of the elevated concentrations of these elements could be such factors as the collapse of the rock in the tunnel area. The watercourse, washing the contaminated fragments of rocks, takes the contaminants and lanthanides to the surface. 


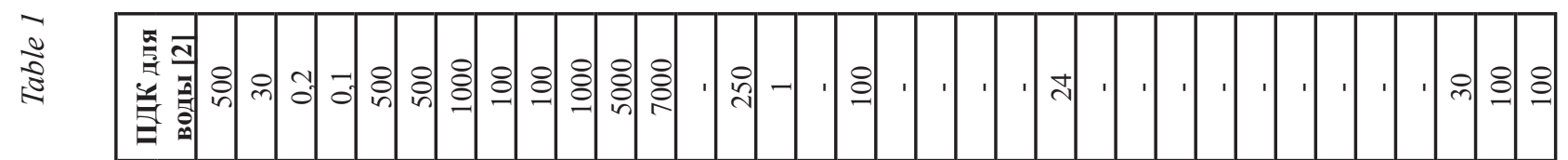

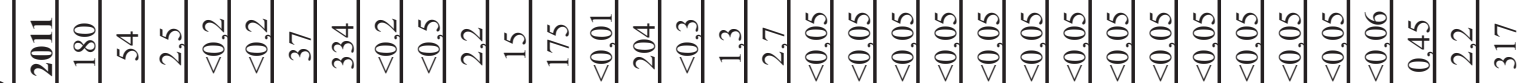
:

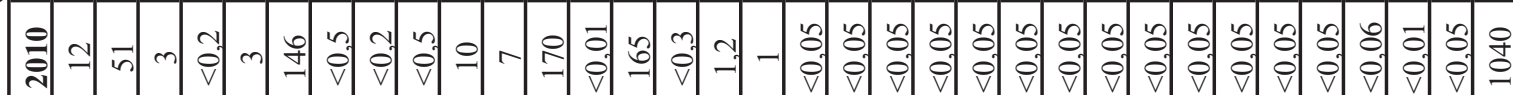

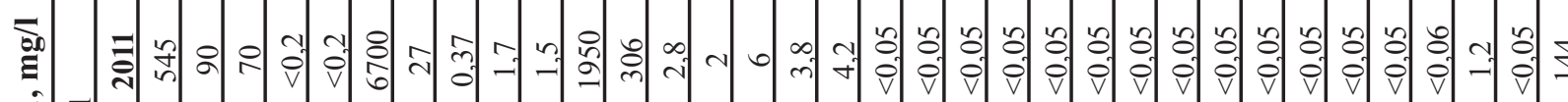
$\overline{\bar{\sigma}} \overline{\text { in }}$

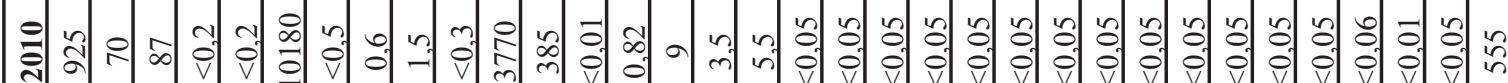

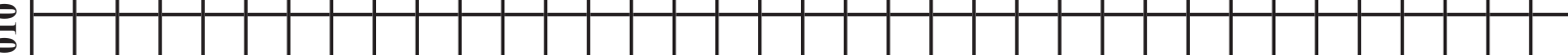

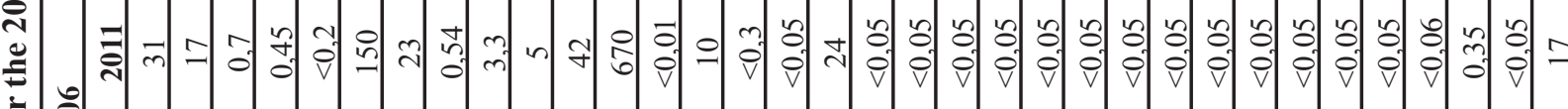
อิ in

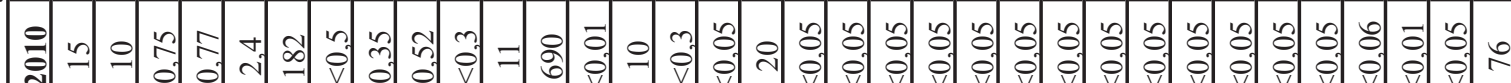

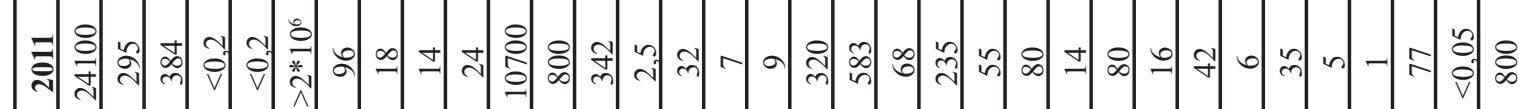
节

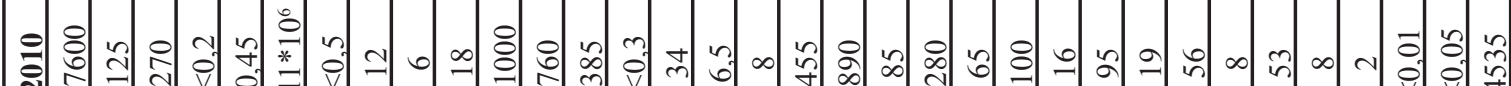

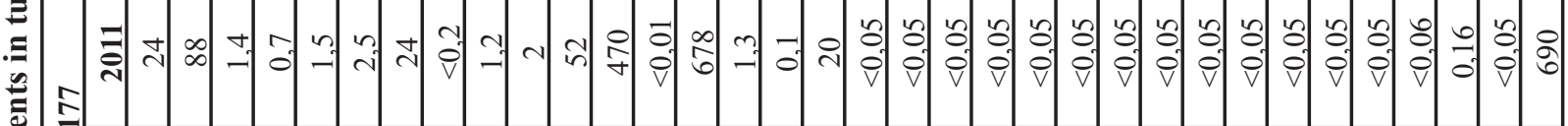
근

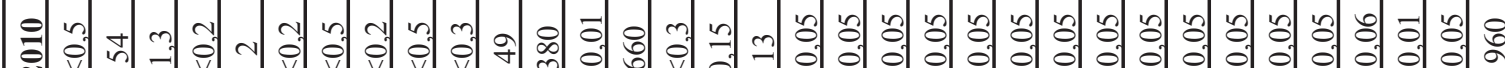

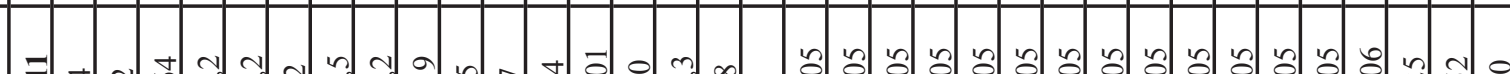
난

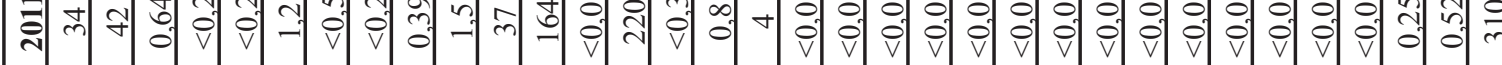

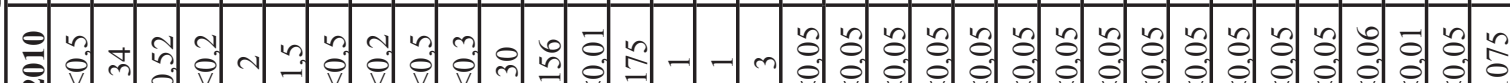

(n) 율

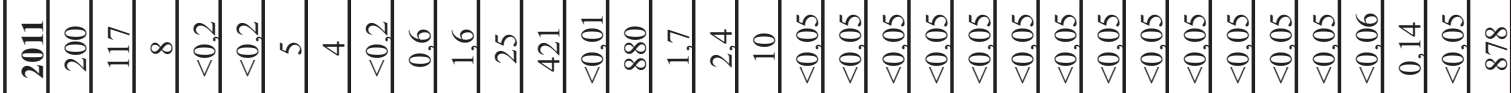
竎

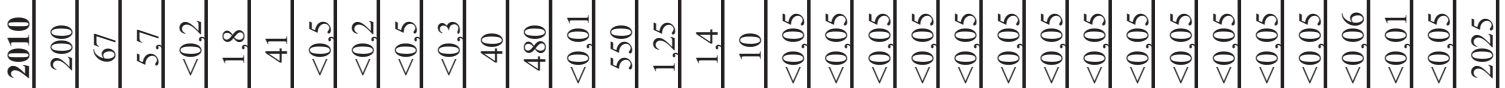
乙 


\section{Assessment of changes in the content of heavy metals in the water during the season}

Figure 2 shows the diagrams of changes in the concentration of elements in time at the exit point of the watercourse to the surface (Figure 2).

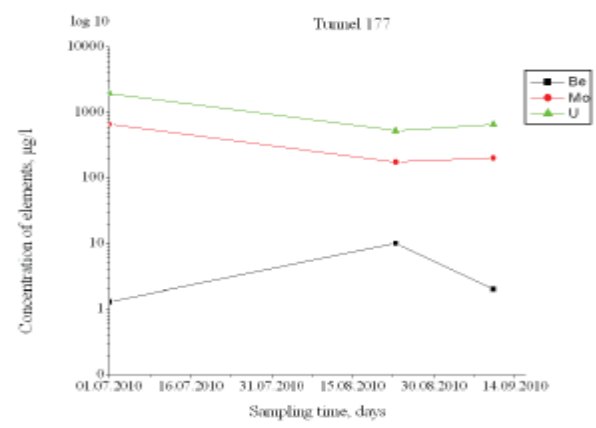

a)

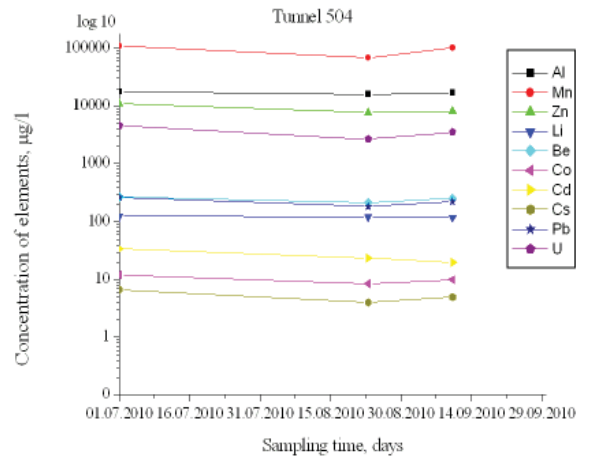

b)

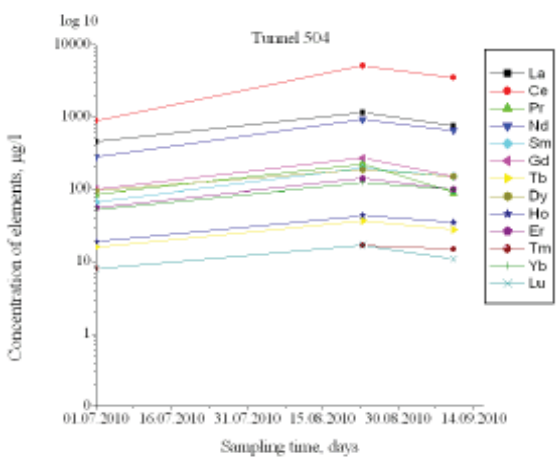

c)

Figure 2. Change in concentrations of elements in the sampling period at the exit point of the watercourse to the surface: a) the tunnel 177, b) tunnel 504, c) tunnel 504

The results presented here suggest that the concentration of the detected elements during the observation period varies slightly, from 5 to $15 \%$. Most streams are characterized by decreasing the concentration of elements in the water in August, possibly due to seasonal changes in flow rate of the watercourse.

However, in the water of tunnel 165 the content of heavy metals during the period of sampling almost does not change. It is also important to note that the maximal content of lanthanides in the water of the tunnel 504 is observed in August, it is also typical beryllium in water of the tunnel 177.

\section{Investigation of variations in the content of heavy metals in the water along the watercourse bed}

Figure 3 shows the diagrams of the variations in the concentrations of some elements in water, depending on the distance from the exit point of water to the surface (Figure 3).

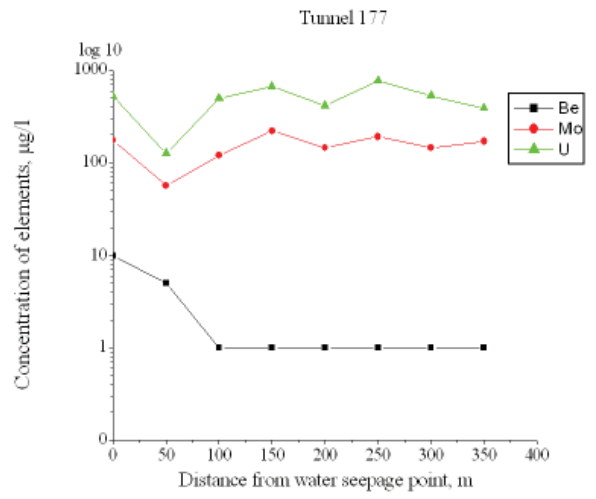

a) 


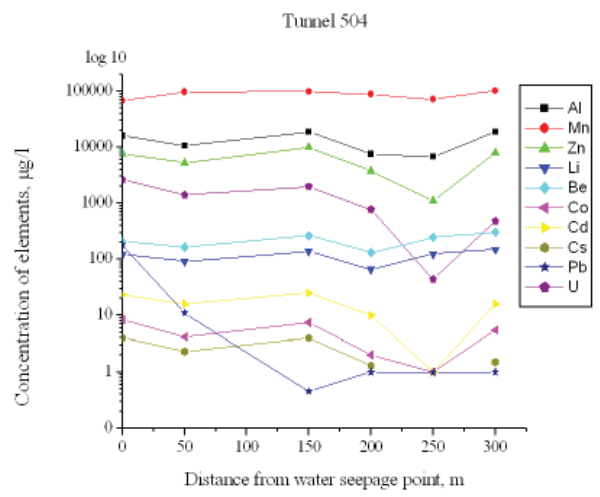

b)

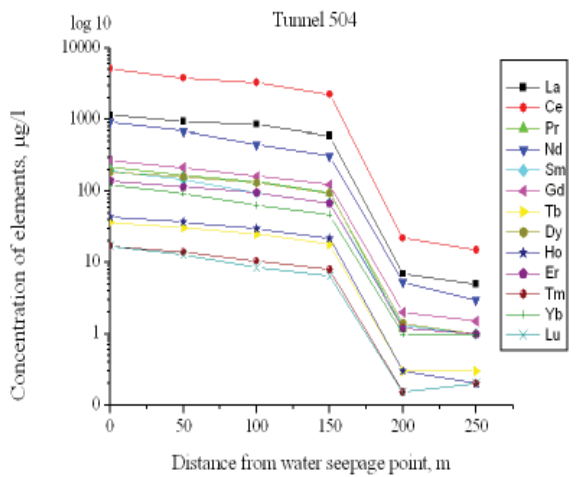

c)

Figure 3. Variations in the concentration of elements in water, depending on the distance from the exit point of water to the surface: a) tunnel 177, b) tunnel 504 , a) tunnel 504

When assessing the results it should be noted that:

1) The content of lanthanides in the water of the tunnel 504 is reduced to almost zero (limit of detection equipment) at a distance of $200 \mathrm{~m}$;

2) Beryllium in the water of all watercourses, except for the tunnels \# 177, \# 506, is detected at a maximal distance from the exit point of water to the surface, which is also associated with the migration properties of this element.

\section{Concentrations of heavy metals in soils of estuarine areas of the tunnel \# 504 and \# 177}

Low "Degelen" mountains are situated within the sub-zone of the zonal light-chestnut soils with desert steppes. The study area is located in the valleys of the streams in the array, where there are intrazonal meadow soils, and very rarely, meadow marsh. The meadow soils were subjected to the greatest contamination. It should be noted that the nearportal areas, where there is maximal pollution, are characterized by artificial substrates, both brought from other sections and collected from this place, mixed with soils. We can assume that here there is an initial stage of soil formation, and this is confirmed by the presence of very small thickness of the humus horizon.

Table 2 shows the average concentration of chemical elements in soil leached solutions, on the sampling profiles, collected along the banks of the watercourse of the tunnel \# 504 (Table 2).

Table 2

Average concentration of elements in the soil leched solutions of the tunnel \# 504

\begin{tabular}{|c|c|c|c|c|c|c|c|c|c|}
\hline Profile \# & $\mathbf{1}$ & $\mathbf{2}$ & $\mathbf{3}$ & $\mathbf{4}$ & $\mathbf{5}$ & $\mathbf{6}$ & \multicolumn{2}{|c|}{$\begin{array}{c}\text { Clarke by } \\
\text { Vinogradov }\end{array}$} \\
\hline \multicolumn{8}{|c|}{$\mathrm{mg} / \mathrm{g}$} \\
\hline $\mathrm{Mn}$ & $4,0 \pm 0,4$ & $3,9 \pm 0,4$ & $12,0 \pm 1,0$ & $5,1 \pm 0,5$ & $14,0 \pm 1,0$ & $17,6 \pm 1,5$ & $13,7 \pm 1,3$ & 1,0 \\
\hline $\mathrm{La}$ & $1,0 \pm 0,1$ & $1,3 \pm 0,1$ & $2,2 \pm 0,2$ & $2,3 \pm 0,2$ & $5,2 \pm 0,5$ & $6,3 \pm 0,6$ & $2,1 \pm 0,2$ & 0,049 \\
\hline $\mathrm{Ce}$ & $5,8 \pm 0,5$ & $6,9 \pm 0,7$ & $11,5 \pm 1,0$ & $10,0 \pm 1,0$ & $19,8 \pm 2,0$ & $19,7 \pm 2,0$ & $5,0 \pm 0,5$ & 0,070 \\
\hline $\mathrm{U}$ & $2,2 \pm 0,2$ & $2,8 \pm 0,2$ & $6,2 \pm 0,6$ & $3,8 \pm 0,3$ & $4,7 \pm 0,4$ & $4,5 \pm 0,4$ & $1,0 \pm 0,1$ & 0,4 \\
\hline $\mathrm{Y}$ & $2,5 \pm 0,2$ & $3,0 \pm 0,3$ & $5,5 \pm 0,5$ & $5,2 \pm 0,5$ & $11,7 \pm 1,0$ & $12,5 \pm 1,0$ & $4,3 \pm 0,4$ & 0,029 \\
\hline $\mathrm{Nd}$ & $1,3 \pm 0,1$ & $1,3 \pm 0,1$ & $2,3 \pm 0,2$ & $2,0 \pm 0,2$ & $3,5 \pm 0,3$ & $3,1 \pm 0,3$ & $0,75 \pm 0,01$ & 0,037 \\
\hline \multicolumn{7}{|c|}{$\operatorname{mcg} / \mathrm{g}$} \\
\hline $\mathrm{Be}$ & $20 \pm 2$ & $32 \pm 3$ & $76 \pm 7$ & $63 \pm 6$ & $141 \pm 14$ & $134 \pm 13$ & $90 \pm 9$ & 3,8 \\
\hline $\mathrm{Sc}$ & $835 \pm 85$ & $680 \pm 70$ & $1230 \pm 125$ & $800 \pm 80$ & $950 \pm 95$ & $1000 \pm 100$ & $420 \pm 45$ & 10 \\
\hline $\mathrm{Li}$ & $35 \pm 3$ & $28 \pm 2$ & $15 \pm 1$ & $30 \pm 3$ & $17 \pm 1$ & $20 \pm 2$ & $32 \pm 3$ & 32 \\
\hline $\mathrm{V}$ & $33 \pm 3$ & $21 \pm 2$ & $12 \pm 1$ & $27 \pm 2$ & $10 \pm 1$ & $13 \pm 1$ & $19 \pm 2$ & 90 \\
\hline $\mathrm{Cr}$ & $23 \pm 2$ & $15 \pm 1$ & $9 \pm 1$ & $19 \pm 2$ & $8,0 \pm 0,7$ & $7,0 \pm 0,6$ & $10 \pm 1$ & 83 \\
\hline $\mathrm{Co}$ & $8,0 \pm 0,7$ & $6,0 \pm 0,6$ & $5,0 \pm 0,4$ & $7,0 \pm 0,6$ & $6,0 \pm 0,5$ & $13,0 \pm 1,0$ & $18,0 \pm 1,5$ & 18 \\
\hline $\mathrm{Ni}$ & $35 \pm 3$ & $32 \pm 3$ & $18 \pm 1$ & $18 \pm 1$ & $17 \pm 1$ & $23 \pm 2$ & $50 \pm 4$ & 58 \\
\hline $\mathrm{Cu}$ & $1200 \pm 100$ & $66 \pm 6$ & $180 \pm 15$ & $140 \pm 10$ & $160 \pm 15$ & $115 \pm 10$ & $45 \pm 4$ & 47 \\
\hline $\mathrm{Zn}$ & $720 \pm 70$ & $530 \pm 50$ & $1000 \pm 80$ & $980 \pm 80$ & $2350 \pm 230$ & $3120 \pm 300$ & $2360 \pm 230$ & 83 \\
\hline $\mathrm{As}$ & $7,0 \pm 0,7$ & $5,5 \pm 0,5$ & $4,5 \pm 0,4$ & $6,0 \pm 0,6$ & $5,0 \pm 0,5$ & $5,5 \pm 0,5$ & $8,0 \pm 0,8$ & 1,7 \\
\hline
\end{tabular}




\begin{tabular}{|c|c|c|c|c|c|c|c|c|}
\hline $\mathrm{Sr}$ & $37 \pm 3$ & $46 \pm 4$ & $135 \pm 15$ & $85 \pm 8$ & $94 \pm 9$ & $82 \pm 8$ & $135 \pm 15$ & 340 \\
\hline $\mathrm{Cd}$ & $2,0 \pm 0,2$ & $2,0 \pm 0,2$ & $2,0 \pm 0,2$ & $3,0 \pm 0,3$ & $5,0 \pm 0,5$ & $9,0 \pm 1,0$ & $6,0 \pm 0,5$ & 0,13 \\
\hline $\mathrm{Cs}$ & $5,0 \pm 0,5$ & $5,0 \pm 0,5$ & $8,0 \pm 0,7$ & $3,0 \pm 0,3$ & $6,0 \pm 0,5$ & $5,0 \pm 0,4$ & $3,0 \pm 0,2$ & 3,7 \\
\hline $\mathrm{Ba}$ & $140 \pm 10$ & $120 \pm 10$ & $120 \pm 10$ & $114 \pm 10$ & $118 \pm 10$ & $200 \pm 15$ & $230 \pm 15$ & 650 \\
\hline $\mathrm{Pr}$ & $320 \pm 30$ & $370 \pm 35$ & $660 \pm 65$ & $580 \pm 60$ & $1150 \pm 100$ & $1000 \pm 100$ & $240 \pm 25$ & 9 \\
\hline $\mathrm{Sm}$ & $360 \pm 35$ & $380 \pm 35$ & $680 \pm 65$ & $430 \pm 45$ & $820 \pm 80$ & $580 \pm 55$ & $150 \pm 15$ & \\
\hline $\mathrm{Gd}$ & $360 \pm 35$ & $400 \pm 40$ & $765 \pm 75$ & $600 \pm 60$ & $1200 \pm 100$ & $1000 \pm 100$ & $280 \pm 25$ & \\
\hline $\mathrm{Tb}$ & $56 \pm 5$ & $63 \pm 6$ & $130 \pm 15$ & $93 \pm 8$ & $180 \pm 15$ & $160 \pm 15$ & $44 \pm 4$ & \\
\hline $\mathrm{Dy}$ & $245 \pm 25$ & $285 \pm 25$ & $560 \pm 55$ & $440 \pm 40$ & $880 \pm 85$ & $780 \pm 75$ & $217 \pm 20$ & 5 \\
\hline $\mathrm{Ho}$ & $60 \pm 6$ & $65 \pm 6$ & $130 \pm 10$ & $110 \pm 10$ & $220 \pm 20$ & $200 \pm 20$ & $49 \pm 5$ & 1,7 \\
\hline $\mathrm{Er}$ & $174 \pm 15$ & $200 \pm 20$ & $390 \pm 40$ & $324 \pm 35$ & $620 \pm 60$ & $578 \pm 55$ & $160 \pm 15$ & 3,3 \\
\hline $\mathrm{Tm}$ & $24 \pm 2$ & $31 \pm 3$ & $55 \pm 5$ & $41 \pm 4$ & $78 \pm 7$ & $77 \pm 7$ & $21 \pm 2$ & \\
\hline $\mathrm{Yb}$ & $180 \pm 15$ & $200 \pm 20$ & $370 \pm 35$ & $250 \pm 25$ & $490 \pm 50$ & $370 \pm 35$ & $100 \pm 10$ & 3,3 \\
\hline $\mathrm{Lu}$ & $27 \pm 2$ & $30 \pm 3$ & $55 \pm 5$ & $36 \pm 4$ & $70 \pm 7$ & $50 \pm 5$ & $12 \pm 1$ & 0,8 \\
\hline $\mathrm{Pb}$ & $765 \pm 75$ & $320 \pm 30$ & $100 \pm 10$ & $40 \pm 4$ & $53 \pm 5$ & $29 \pm 3$ & $32 \pm 3$ & 16 \\
\hline
\end{tabular}

To identify the most important elements - the main pollutants, a method was used to compare these results with an average content of elements in the soil (Clarke), although this is not correct with respect to the acid digest, as Clarke implies total content of elements in the soil. The comparison revealed that the major pollutants of soil for the tunnel \#504 are such elements as $\mathrm{Be}, \mathrm{U}$ and rare earth elements (REE).

For the elements that are present in abnormal amounts, maps, diagrams of the spatial distribution of elements were constructed (Figure 4).

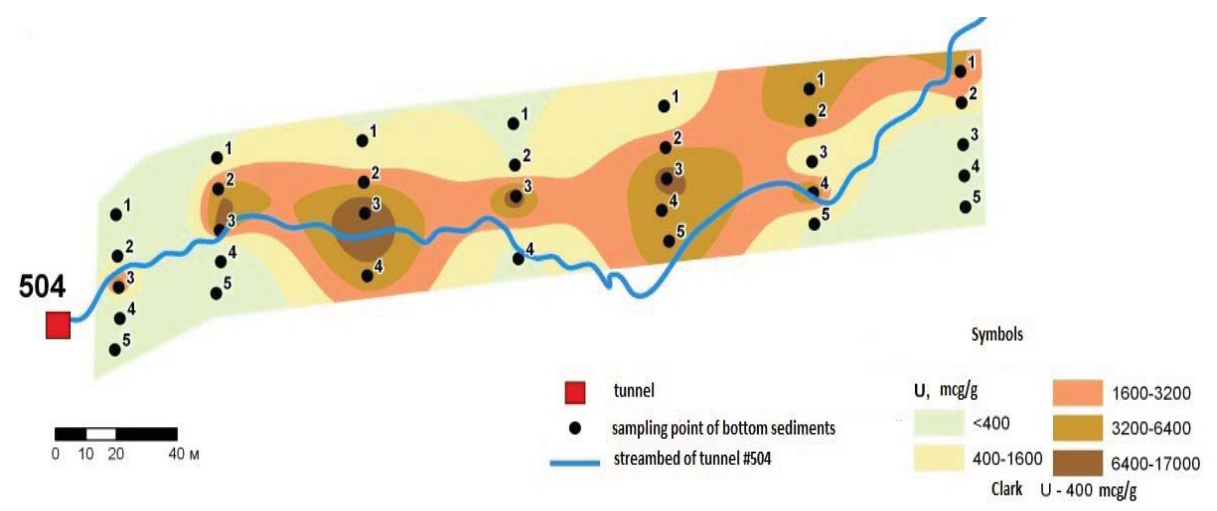

a)

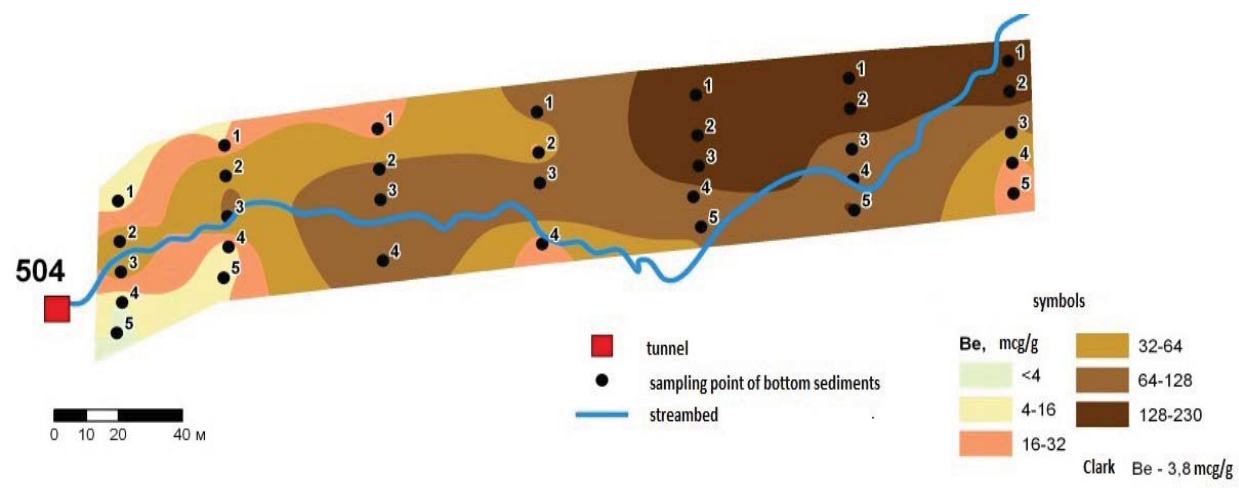

b) 


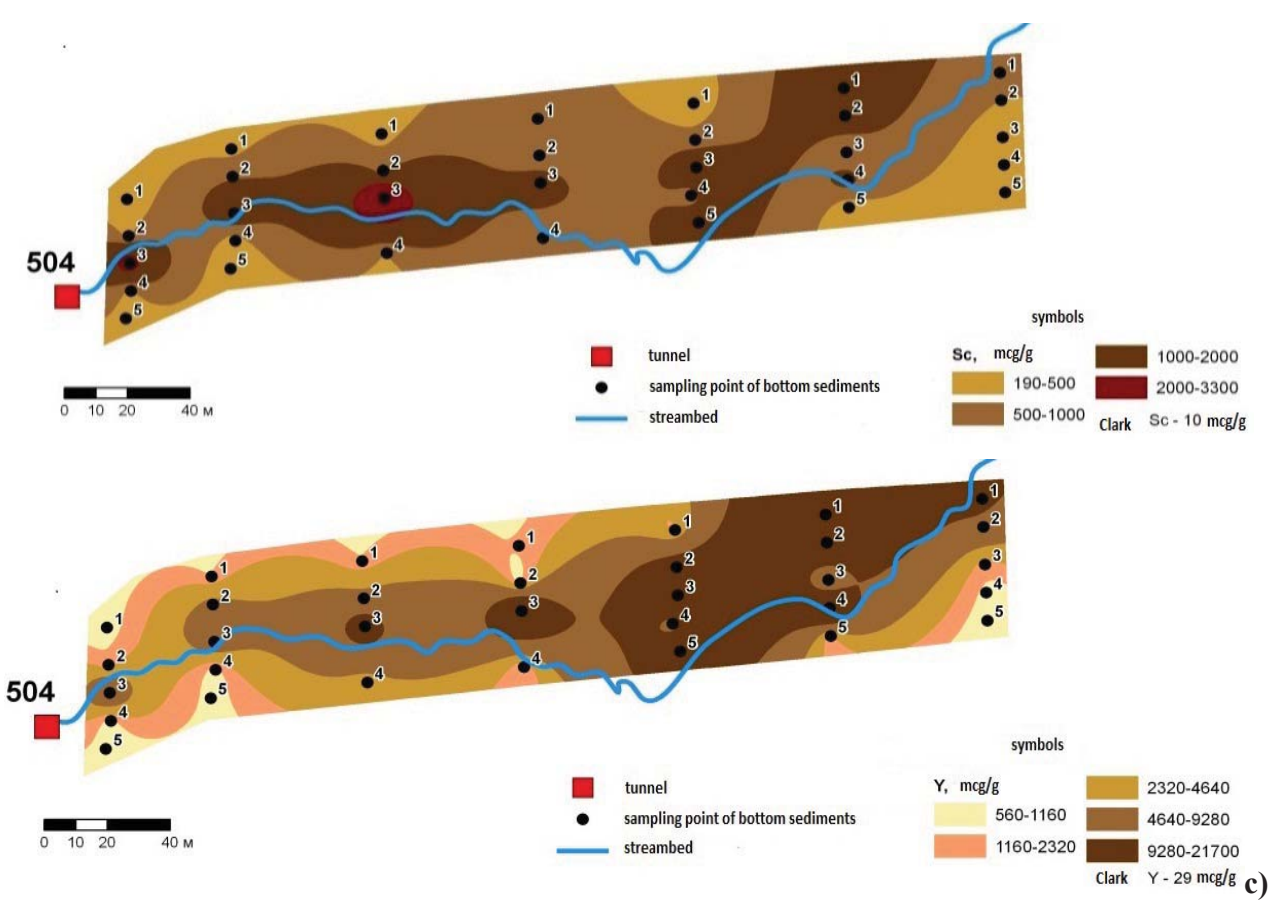

d)

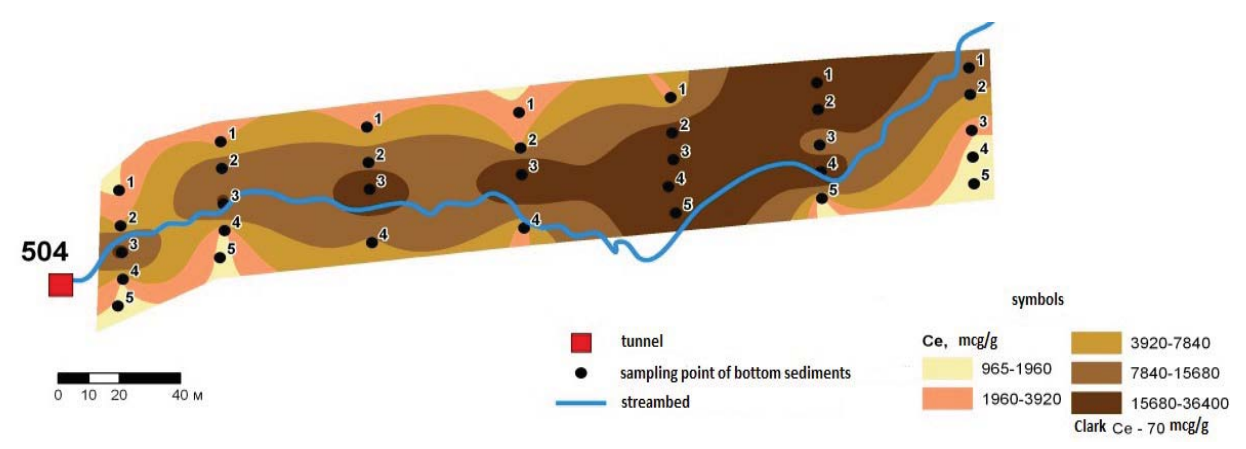

e)

Figure 4: Spatial pattern of distribution of some elements in the soil at the near-portal areas of thetunnel \#504: a) uranium, b) beryllium, c) scandium, d) yttrium, e) cerium

Analysis of data on the spatial distribution showed that such elements as uranium, beryllium, and lanthanides are concentrated in the immediate vicinity of the watercourse, and the points with a maximal content are confined to the stream bed.

For a more visual representation Figure 5 shows the typical distribution of the concentration of lanthanum and yttrium elements in soil leached solution on the perpendicular profile (Figure 5).

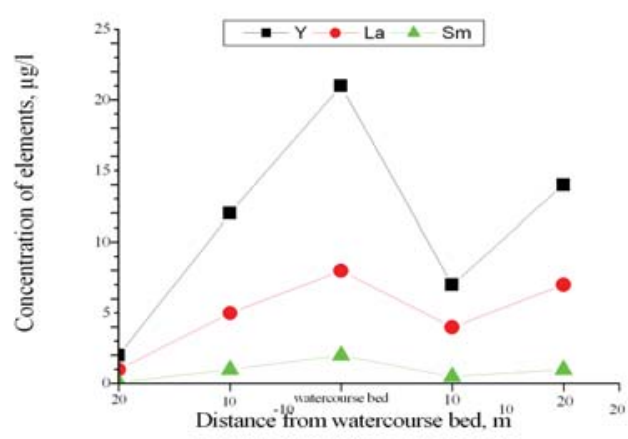

Figure 5. Typical distribution of elements in soil leached solutions of the tunnel \#504 on the sampling profile 
An analysis of the results suggests that the points with the highest concentration of elements are found in the streambed, the levels of heavy metals in the soil at a distance of $20 \mathrm{~m}$ from the channel are reduced 10 times.

This suggests that contamination of the near-portal areas is caused by carry-over of lanthanides by tunnel waters and is not related to their content in the soil itself of the near-portal area.

Table 3 presents the concentrations of chemical elements in soil leached solutions on sampling profiles at the tunnel \# 177 (Table 3).

Table 3

Average concentration of elements in the soil leached solutions of the tunnel \# 177

\begin{tabular}{|c|c|c|c|c|c|c|c|c|}
\hline Profile \# & 1 & 2 & 3 & 4 & 5 & 6 & 7 & $\begin{array}{l}\text { Clarke by } \\
\text { Vinogradov } \\
\end{array}$ \\
\hline \multicolumn{9}{|c|}{$\mathrm{mcg} / \mathrm{g}$} \\
\hline $\mathrm{Li}$ & $25 \pm 2$ & $20 \pm 2$ & $21 \pm 2$ & $20 \pm 2$ & $26 \pm 2$ & $23 \pm 2$ & $25 \pm 2$ & 32 \\
\hline $\mathrm{Be}$ & $14 \pm 1$ & $7,0 \pm 0,7$ & $4,0 \pm 0,4$ & $10 \pm 1$ & $3,0 \pm 0,3$ & $5,0 \pm 0,5$ & $3,0 \pm 0,3$ & 3,8 \\
\hline $\mathrm{Sc}$ & $260 \pm 25$ & $170 \pm 15$ & $180 \pm 15$ & $200 \pm 20$ & $270 \pm 25$ & $230 \pm 20$ & $230 \pm 20$ & 10 \\
\hline $\mathrm{V}$ & $35 \pm 3$ & $28 \pm 2$ & $30 \pm 3$ & $34 \pm 3$ & $44 \pm 4$ & $39 \pm 4$ & $40 \pm 4$ & 90 \\
\hline $\mathrm{Cr}$ & $31 \pm 3$ & $22 \pm 2$ & $21 \pm 2$ & $25 \pm 2$ & $30 \pm 3$ & $27 \pm 2$ & $27 \pm 2$ & 83 \\
\hline $\mathrm{Mn}$ & $450 \pm 45$ & $650 \pm 60$ & $710 \pm 70$ & $920 \pm 90$ & $970 \pm 90$ & $1280 \pm 120$ & $800 \pm 80$ & 1000 \\
\hline $\mathrm{Co}$ & $5,0 \pm 0,4$ & $5,0 \pm 0,4$ & $5,0 \pm 0,4$ & $5,0 \pm 0,4$ & $7,0 \pm 0,6$ & $7,0 \pm 0,6$ & $7,0 \pm 0,6$ & 18 \\
\hline $\mathrm{Ni}$ & $<0,5$ & $6,0 \pm 0,5$ & $23 \pm 2$ & $<0,5$ & $14 \pm 1$ & $<0,5$ & $<0,5$ & 58 \\
\hline $\mathrm{Cu}$ & $53 \pm 4$ & $54 \pm 4$ & $33 \pm 3$ & $40 \pm 4$ & $29 \pm 3$ & $28 \pm 3$ & $24 \pm 2$ & 47 \\
\hline $\mathrm{Zn}$ & $210 \pm 20$ & $160 \pm 15$ & $145 \pm 15$ & $220 \pm 20$ & $105 \pm 10$ & $156 \pm 14$ & $100 \pm 8$ & 83 \\
\hline $\mathrm{Sr}$ & $127 \pm 10$ & $127 \pm 10$ & $78 \pm 7$ & $79 \pm 7$ & $100 \pm 8$ & $63 \pm 5$ & $55 \pm 4$ & 340 \\
\hline $\mathrm{Y}$ & $1400 \pm 140$ & $720 \pm 70$ & $670 \pm 65$ & $750 \pm 70$ & $830 \pm 80$ & $780 \pm 75$ & $700 \pm 65$ & 29 \\
\hline $\mathrm{Cd}$ & $2,0 \pm 0,2$ & $<0,6$ & $<0,6$ & $2,0 \pm 0,2$ & $1,0 \pm 0,1$ & $1,0 \pm 0,1$ & $<0,6$ & 0,13 \\
\hline $\mathrm{Cs}$ & $4,0 \pm 0,3$ & $3,0 \pm 0,2$ & $2,0 \pm 0,2$ & $2,0 \pm 0,2$ & $3,0 \pm 0,3$ & $3,0 \pm 0,3$ & $3,0 \pm 0,3$ & 3,7 \\
\hline $\mathrm{Ba}$ & $165 \pm 15$ & $150 \pm 15$ & $130 \pm 10$ & $140 \pm 10$ & $260 \pm 20$ & $220 \pm 20$ & $170 \pm 15$ & 650 \\
\hline $\mathrm{La}$ & $510 \pm 50$ & $390 \pm 35$ & $420 \pm 40$ & $440 \pm 40$ & $550 \pm 50$ & $530 \pm 50$ & $510 \pm 50$ & 49 \\
\hline $\mathrm{Ce}$ & $2000 \pm 200$ & $1700 \pm 150$ & $2200 \pm 200$ & $2100 \pm 200$ & $3200 \pm 300$ & $3100 \pm 300$ & $2800 \pm 250$ & 70 \\
\hline $\operatorname{Pr}$ & $120 \pm 10$ & $90 \pm 9$ & $100 \pm 10$ & $100 \pm 10$ & $135 \pm 12$ & $130 \pm 12$ & $120 \pm 10$ & 9 \\
\hline $\mathrm{Nd}$ & $510 \pm 50$ & $370 \pm 35$ & $400 \pm 40$ & $400 \pm 40$ & $470 \pm 45$ & $460 \pm 45$ & $450 \pm 45$ & 37 \\
\hline $\mathrm{Sm}$ & $100 \pm 10$ & $70 \pm 7$ & $71 \pm 7$ & $74 \pm 7$ & $96 \pm 8$ & $91 \pm 8$ & $87 \pm 8$ & \\
\hline $\mathrm{Gd}$ & $120 \pm 10$ & $76 \pm 7$ & $73 \pm 7$ & $78 \pm 7$ & $106 \pm 10$ & $99 \pm 10$ & $97 \pm 9$ & \\
\hline $\mathrm{Tb}$ & $13,0 \pm 1,0$ & $6,5 \pm 0,6$ & $6,0 \pm 0,6$ & $6,5 \pm 0,6$ & $9,0 \pm 0,8$ & $7,5 \pm 0,7$ & $8,5 \pm 0,8$ & \\
\hline Dy & $72 \pm 7$ & $40 \pm 4$ & $39 \pm 4$ & $43 \pm 4$ & $56 \pm 5$ & $53 \pm 5$ & $50 \pm 5$ & 5 \\
\hline Ho & $16,0 \pm 1,5$ & $8,0 \pm 0,8$ & $7,5 \pm 0,7$ & $8,5 \pm 0,8$ & $10,0 \pm 1,0$ & $10,0 \pm 1,0$ & $9,0 \pm 0,8$ & 1,7 \\
\hline $\mathrm{Er}$ & $55 \pm 5$ & $28 \pm 2$ & $27 \pm 2$ & $29 \pm 2$ & $39 \pm 3$ & $35 \pm 3$ & $32 \pm 3$ & 3,3 \\
\hline $\mathrm{Tm}$ & $5,0 \pm 0,5$ & $2,0 \pm 0,2$ & $1,0 \pm 0,1$ & $1,0 \pm 0,1$ & $2,0 \pm 0,2$ & $1,0 \pm 0,1$ & $1,0 \pm 0,1$ & \\
\hline $\mathrm{Yb}$ & $50 \pm 5$ & $25 \pm 2$ & $24 \pm 2$ & $27 \pm 2$ & $33 \pm 3$ & $30 \pm 3$ & $26 \pm 2$ & 3,3 \\
\hline $\mathrm{Lu}$ & $5,0 \pm 0,5$ & $3,0 \pm 0,3$ & $1,0 \pm 0,1$ & $1,0 \pm 0,1$ & $2,0 \pm 0,2$ & $2,0 \pm 0,2$ & $1,0 \pm 0,1$ & 0,8 \\
\hline $\mathrm{Pb}$ & $25 \pm 2$ & $33 \pm 3$ & $22 \pm 2$ & $29 \pm 3$ & $33 \pm 3$ & $39 \pm 3$ & $27 \pm 3$ & 16 \\
\hline $\mathrm{U}$ & $271 \pm 25$ & $48 \pm 4$ & $132 \pm 15$ & $106 \pm 10$ & $42 \pm 4$ & $70 \pm 7$ & $47 \pm 4$ & \\
\hline
\end{tabular}

Applying the already used method of comparison with Clarke identified the following a series of elements which are considered as components of the major pollutants: Be, Y, U, Ce, Pr, Cd. Maps of the spatial distribution of these elements were built (Figure 6).

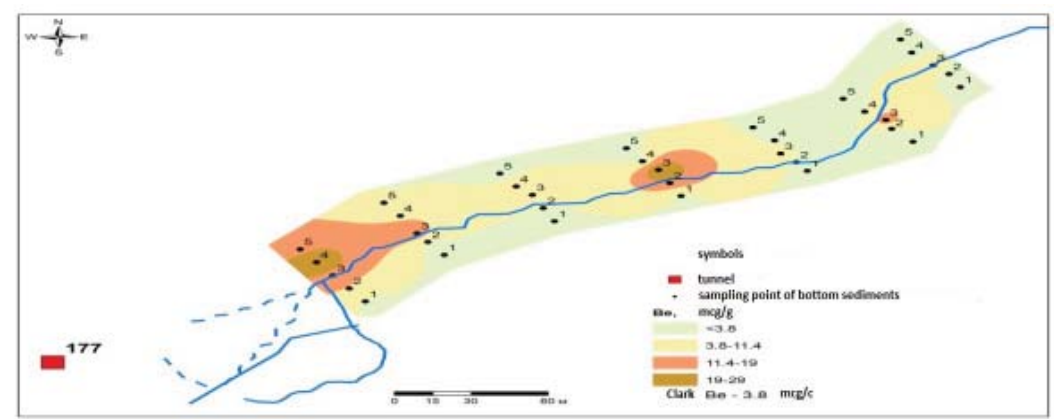

a) 


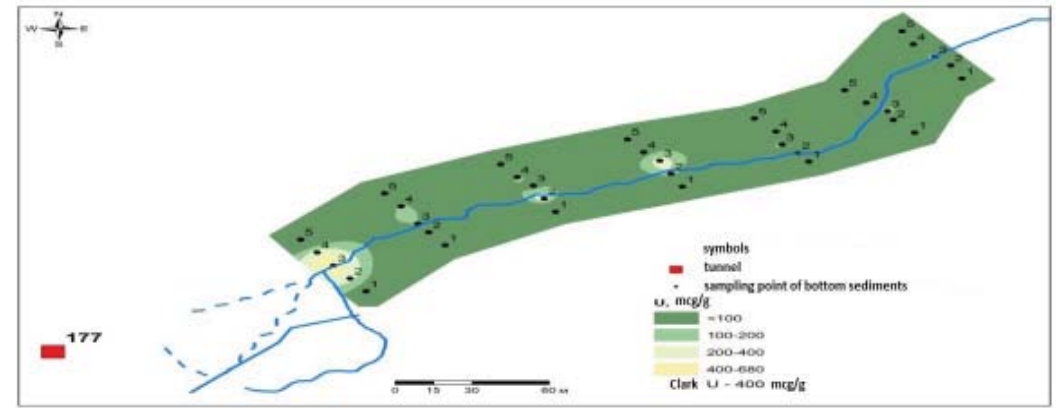

b)

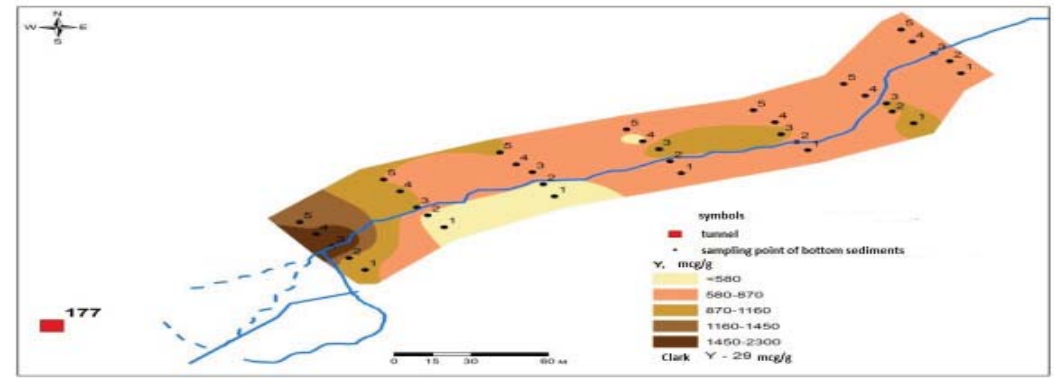

c)

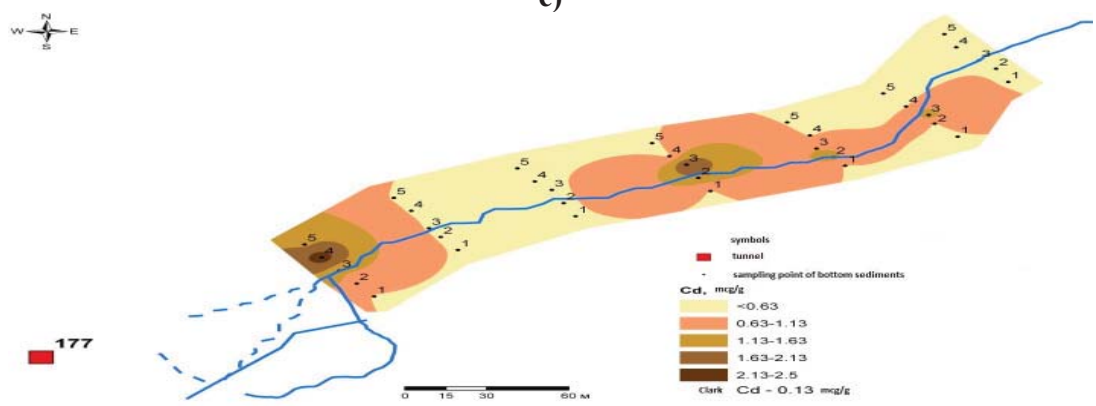

d)

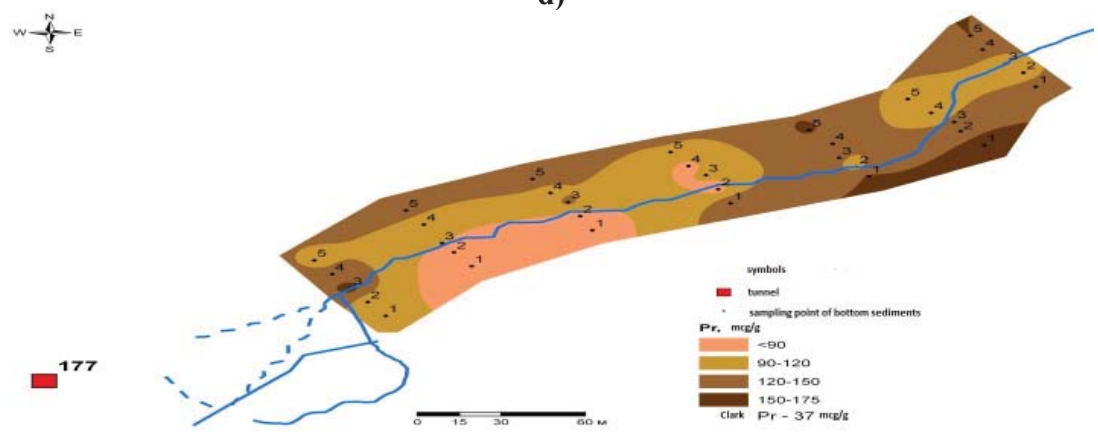

e)

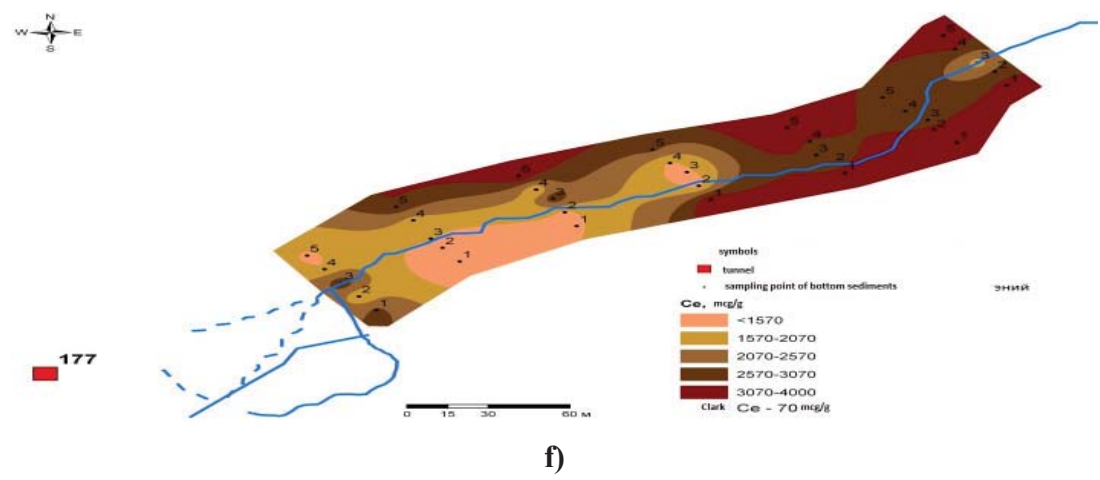

Figure 6. Spatial pattern of distribution of some elements in the soil at the near-portal areas of the tunnel \#177: a) beryllium, b) uranium, c) yttrium, d) cadmium, e) praseodymium, f) cerium 
The soil of the tunnels also had subgroups of lanthanum elements, but in the water of the watercourse they are not found. Probably the highest concentrations of these elements are not the consequence of their carry-over by tunnel waters, but due to the geochemical features of the studied area. This fact is confirmed by the spatial distribution of the identified elements, the maximal contents of the studied elements are not in the streambed (Figure 7).

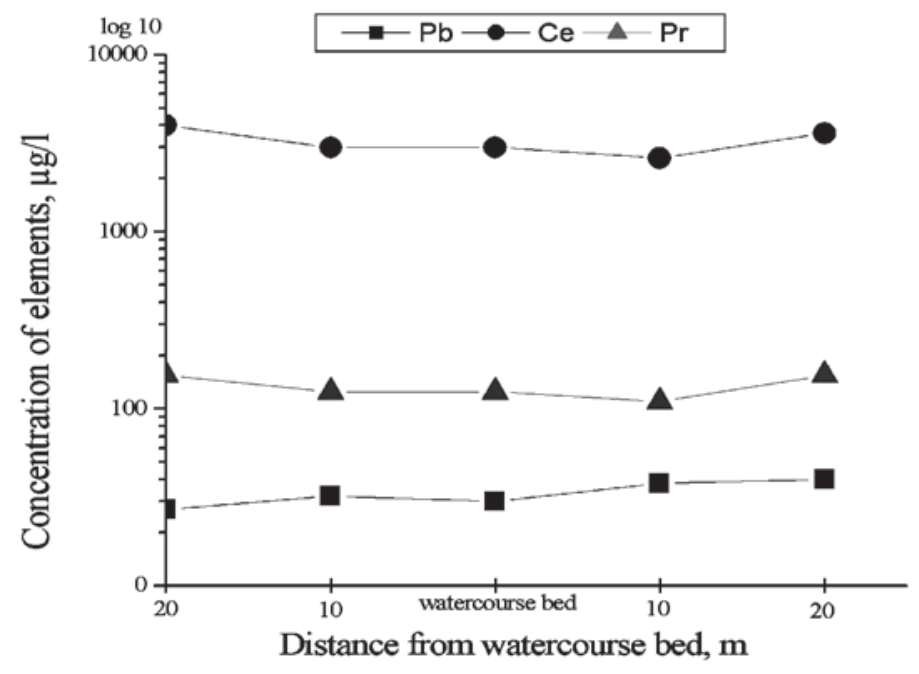

Figure 7: Typical distribution of elements in soil leached solutions at the tunnels \# 177 on the sampling profile

\section{Concentrations of heavy metals in the plants at the estuarine areas of the tunnel \#504}

The vegetation of the valleys of streams, are mostly represented by marshy (Phragmites australis, Ligularia macrophilla), natural (Calamagrostis epigeios, Glycyrrhiza uralensis), steppificated (Poa trivialis, Galatella biflora), halophytic (Achnatherum splendens, Liminium gmelinii) variants of meadows, bushland of Salix cinerea, Rosa glabrifolia is distributed piecewise.

During the reconnaissance the vegetation was described not only to identify the communities and the dominant species, but also provide a complete picture of the flora of the investigated area. Thus, such species as bush grass (Calamagróstis epigéjos), southern reed south (Phrágmites austrális), sedge grass (Carex supina), weeping birch (Bétula péndula), gray willow (Salix cinerea), naked-leaved briar (Rosa glabrifolia), black-fruited cotoneaster (Cotoneaster melanocarpus Fisch), tutsan-leaved meadowsweet (Spiraea hypericifolia) fescue (Festuca valesiaca), feather capilata (Stipa capillata), Austrian wormwood (Artemisia austriaca), estragon (Artemisia dracunculus), narrow-leaved wild rye (Leymus angustus), highland wheat (Orostachys spinosa), greater burnet (Sanguisórba officinális).

As mentioned earlier, the soil cover at the near-portal areas are characterized by artificial substrate with sparse vegetation, represented mostly by weedy species. They grow on such areas by the type of primary succession. It consists of several stages. The first - colony of individual plants with the differentiation by substrate and microrelief. The formation rate of secondary vegetation is directly dependent on the particle size (no growth at very rocky areas of the near portal-areas). Firstly weedy and adventive species are settled: Amaranthus retroflexus, Ceratocarpus arenaria, Artemisia scoparia, Kochia scoparia, Acroptilon repens, Fumaria vailantii. Further there is a distribution of vegetation in altitudinal belts and microrelief. The following stages are sparse groupings dominated by species of the genus Artemisia, meadow grasses - Medicago falcata, Galatella, Achillea asiatica - grasses: Stipa capillata, Psathyrostachys juncea, Festuca valesiaca, Agropiron cristatum.

Table 4 presents the average concentrations of chemical elements in the sampling profiles in the samples of plants, selected on the bed of the watercourse and the territory adjacent to the tunnel \#504 (Table 4).

Table 4

Average concentration of elements in plant samples

\begin{tabular}{|c|c|c|c|c|c|c|c|}
\hline Profile \# & 1 & 2 & 3 & 4 & 5 & 6 & 7 \\
\hline & \multicolumn{7}{|c|}{$\mathrm{mcg} / \mathrm{g}$} \\
\hline $\mathrm{Al}$ & 300,0 & 324,7 & 491,8 & 231,3 & 167,8 & 144,3 & 289,5 \\
\hline $\mathrm{Cr}$ & 5,9 & 4,0 & 2,9 & 2,5 & 5,3 & 4,9 & 5,0 \\
\hline $\mathrm{Zn}$ & 133,0 & 145,6 & 470,2 & 506,4 & 105,1 & 64,4 & 62,9 \\
\hline $\mathrm{Cd}$ & 0,9 & 0,5 & 0,8 & 0,7 & 0,4 & 0,4 & 0,4 \\
\hline
\end{tabular}




\begin{tabular}{|c|c|c|c|c|c|c|c|}
\hline $\mathrm{Pb}$ & 7,3 & 5,6 & 2,8 & 2,4 & 1,7 & 4,1 & 2,8 \\
\hline $\mathrm{Sr}$ & 48,9 & 25,0 & 30,5 & 42,7 & 16,1 & 10,9 & 24,5 \\
\hline $\mathrm{U}$ & 5,0 & 2,6 & 4,0 & 0,8 & 1,2 & 1,9 & 9,6 \\
\hline $\mathrm{Cu}$ & 22,8 & 17,4 & 8,7 & 7,1 & 5,0 & 6,2 & 2,8 \\
\hline $\mathrm{Mn}$ & 1250,5 & 1790,3 & 5302,4 & 7059,0 & 1562,7 & 1738,7 & 2096,5 \\
\hline $\mathrm{Be}$ & 2,8 & 3,6 & 10,8 & 7,3 & 3,5 & 3,3 & 3,6 \\
\hline $\mathrm{Li}$ & 13,7 & 6,9 & 5,5 & 5,1 & 14,6 & 4,9 & 3,3 \\
\hline $\mathrm{Co}$ & 0,4 & 0,4 & 0,4 & 0,4 & 0,4 & 0,4 & 0,4 \\
\hline $\mathrm{Ni}$ & 4,0 & 2,9 & 3,9 & 2,8 & 3,3 & 3,2 & 3,4 \\
\hline $\mathrm{Rb}$ & 5,1 & 12,8 & 3,4 & 4,3 & 13,5 & 16,2 & 5,8 \\
\hline $\mathrm{Y}$ & 1,7 & 1,9 & 2,0 & 0,3 & 0,9 & 0,9 & 5,6 \\
\hline $\mathrm{La}$ & 1,7 & 1,8 & 1,9 & 0,4 & 0,9 & 1,0 & 5,0 \\
\hline $\mathrm{Ce}$ & 2,8 & 3,0 & 3,1 & 0,6 & 1,2 & 1,4 & 7,2 \\
\hline $\mathrm{Nd}$ & 1,2 & 1,3 & 1,2 & 0,2 & 0,4 & 0,5 & 2,6 \\
\hline $\mathrm{Sm}$ & 0,3 & 0,3 & 0,3 & 0,1 & 0,1 & 0,1 & 0,5 \\
\hline $\mathrm{Fe}$ & 264,0 & 322,3 & 262,6 & 248,1 & 172,2 & 169,4 & 173,0 \\
\hline $\mathrm{Gd}$ & 0,4 & 0,4 & 0,5 & 0,1 & 0,2 & 0,2 & 1,0 \\
\hline
\end{tabular}

Figure 8 shows the diagrams of the variations in the concentrations of some elements in plant samples

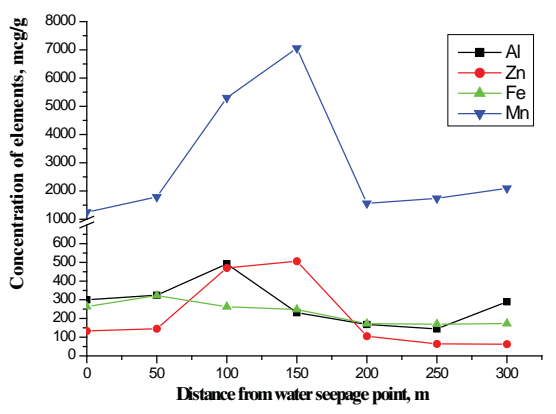

a)

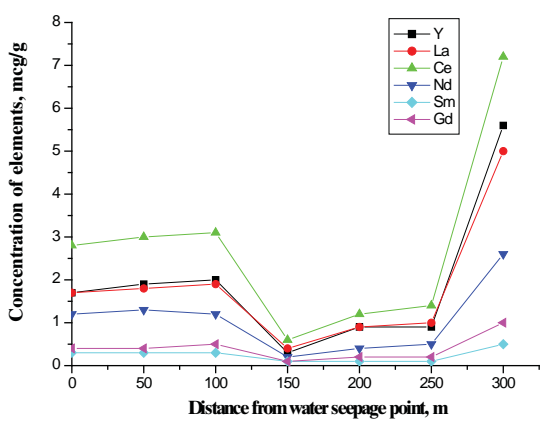

c)

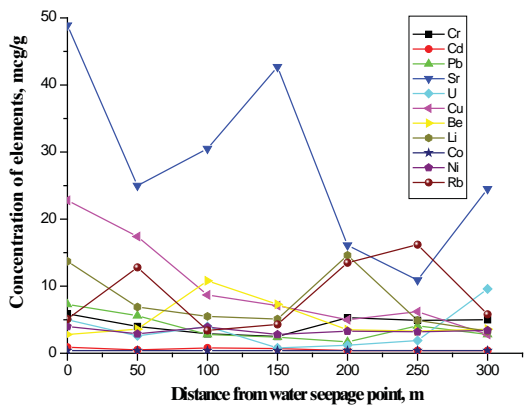

b)

Figure 5. Variations in the concentration of elements in plant samples of the tunnel $\# 504$ on the sampling profile

Analysis of the results suggests that the point with the highest concentration of elements such as Al, Zn, Mn located at a distance of 100-150 m (2.3 profile) from the exit site of the watercourse to the surface.

The concentration of lanthanides in plant samples is reduced to almost zero at a distance of $150 \mathrm{~m}$ and increases sharply at a distance of $300 \mathrm{~m}$ from the exit site of the watercourse to the surface. The uneven distribution of elements of the subgroup of lanthanum due primarily to the fact that the flow of the lanthanides in plants is carried out by the removal of these elements shtolnevymi waters, rather than their content in the soil itself, on which grow the studied species.

Penetration of heavy metals in plants through the root system depends primarily on the amount of these metals in the soil. The correlation coefficients between the content of metals in plants and environments under different conditions (soil type, moisture, acidity, etc.) can be quite high - in some cases exceeds the value 0.80 . There are both linear and nonlinear increases of metal content with increasing their concentration in solution or culture media. 
The contents of excessive amounts of heavy metals in the plant mass may vary during the growing season. One of the reasons of this is the inability of the stream coming from the soil into plants evenly throughout the growing season to saturate biomass growth with heavy metals, which in mid-summer reaches the peak, and although the rate of their income is more or less uniform, there is a so-called "dilution effect".

\section{Conclusion}

The above experimental data allow us to consider the environmental situation in the STS, particularly at Degelen site as a complex system of radiative and "nonradiative" factors. The main conclusions of this work can be considered as follows:

- all the investigated tunnel waters are characterized by higher concentrations of uranium, beryllium, and molybdenum, at that, molybdenum level in the water of some tunnels (tunnel \#104) exceeds the typical content in the water for the climate up to 800 times;

- water of the tunnel \#504 is absolutely unique for its elemental composition, in particular, for the content of lanthanum elements subgroup (total REE $\sim 4 \mathrm{mg} / \mathrm{l}$ ), as well as the content of aluminum, manganese, zinc, the concentrations of which are comparable to the concentrations of macro-components;

- high content in plants such elements as aluminum, zinc and manganese as well as in water is comparable to the concentrations of macro-components;

- analysis of the results on the content comparable by radiotoxicity $\alpha$-nuclides of the natural isotope ${ }^{238} \mathrm{U}$ and plutonium isotopes ${ }^{239+240} \mathrm{Pu}$ showed greater significance of natural uranium for the studied waters in terms of radiation hazards and potential dose loads. In this connection, it is necessary to consider this factor when assessing the radiation hazard of the STS facilities;

- elevated concentrations of rare-earth metals in the soil and plants at estuarine area of the tunnel \#504 are associated with the carry-over of heavy metals by water from a watercourse of the tunnel. Soil of the tunnel \#177 also has high amounts of REM, but the reason for this is the geochemical characteristics of the area.

\section{Acknowledgments}

The authors wish to thank all the staff of the Institute of Radiation Safety and Ecology NNC RK for their assistance in organizing field works and processing the data, as well as members of the Institute of Nuclear Physics NNC for the analyses made.

\section{References}

[1]. Под редакцией Лукашенко С.Н., Семипалатинский испытательный полигон. Современное состояние. Курчатов, 2008 г; с. 12.

[2]. Под редакцией Лукашенко С.Н., Сборник трудов Института радиационной безопасности и экологии за 2007-2009 гг. ДГП Институт радиационной безопасности и экологии РГП НЯЦ РК, 2010 г., с 451-460.

[3]. Энерглин У., Брили Л. «Аналитическая геохимия», Л.: НЕДРА, 1975.

[4]. Соловов А.П. «Геохимические методы поисков месторождений полезных ископаемых», М.: НЕДРА, 1976.

[5]. «Иллюстрированный определитель растений Казахстана» Том I. Академия наук Казахской ССР, Институт ботаники, изд. «Наука» Казахской ССР, Алма-Ата 1969 г., с 79, 86, 489, 518, 229-230.

[6]. «Иллюстрированный определитель растений Казахстана» Том I. Академия наук Казахской ССР, Институт ботаники, изд. «Наука» Казахской ССР, Алма-Ата 1972 г., с 483.

[7]. Виноградов А.П. «Среднее содержание химических элементов в главных типах изверженных горных пород земной коры», Геохимия, 1962 №7.

[8]. Шоу Д.М. «Геохимия микроэлементов кристаллических пород», Л: НЕДРА, 1969.

[9]. Isotopic Compositions of the Elements 1989, Pure Appl.,Chem.,Vol.63, No.7

[10]. Шварцев С.Л. «Гидрогеохимия зоны гипергенеза», М.: НЕДРА, 1998.

[11]. СанПиН 2.1.4.1074-01.

[12]. Давыдов С.Л., Тагасов В.И. «Тяжелые металлы как супертоксиканты XXI века», М.: РУДН, 2002.

[13]. Беус А.А., Грабовская Л.И., Тихонова Н.В. «Геохимия окружающей среды», М.: НЕДРА, 1976. 